\title{
CES
}

COOPERATIVISMO E ECONOMÍA SOCIAL

Núm. 43 (2020-2021), páxs. 123-147

ISSN: 2660-6348

\section{OS PERFIS PROFISSIONAIS DE AGENTES DE INSERÇÃO DAS ORGANIZAÇÕES DA ECONOMIA SOCIAL}

\section{THE PROFESSIONAL PROFILES OF INSERTION AGENTS FROM SOCIAL ECONOMY ORGANIZATIONS}

\author{
Ana Luísa Martinho* \\ MAFALDA GoMes**
}

Recepción: 2/10/2021 - Aceptación: 10/10/2021

\footnotetext{
* Mestre com título de especialista, Professora Adjunta Convidada no ISCAP, Universitat de València, CEOS.PP/ISCAP/P.Porto, Associação A3S, analuisa.martinho@gmail.com. Correio postal: Instituto Superior de Contabilidade e Administração do Porto, Rua Jaime Lopes de Amorim, 4465-004 S. Mamede de Infesta, Portugal.

** Mestre, Socióloga, Universitat de València, Associação A3S, CEOS.PP, maffagomes@gmail.com. Correio postal: Instituto Superior de Contabilidade e Administração do Porto, Rua Jaime Lopes de Amorim, 4465-004 S. Mamede de Infesta, Portugal.
} 


\section{RESUMO}

Os perfis profissionais constituem um objeto de estudo em permanente reflexão pela Sociologia (Bourdieu, 1989; Dubar, 1991). Escasseiam, contudo, em Portugal, trabalhos sobre os perfis profissionais de trabalhadores da Economia Social, setor com potencial reconhecido para a economia e desenvolvimento de um país (INE, 2020). Este artigo baseia-se nos resultados parciais de duas investigações que têm em comum o estudo, a partir de uma abordagem qualitativa, dos perfis profissionais associados às funções de acompanhamento de pessoas com experiências de "desinserção social" (Paugam, 2000). As respostas ao nível da formação específica destes profissionais não acompanham a tendência de estruturação do setor. Os resultados apresentados apontam para a complexidade e exigência do perfil profissional que designamos de "Agente de Inserção", cuja intervenção acontece num setor que lida com múltiplas problemáticas, em que escasseiam orientações sobre a definição das suas funções e nas quais se evidenciam competências de relação empática com os públicos alvos das intervenções.

Palavras Chave: Economia social; perfis profissionais; inserção social; profissionalização

\section{ABSTRACT}

Professional profiles are a study object under permanent reflection by Sociology (Bourdieu, 1989; Dubar, 1991). There is, however, a shortage of work in Portugal on the professional profiles of Social Economy workers, a sector with recognised potential for the country's economy and development (INE, 2020). This article is based on the partial results of two researches that have in common the study, from a qualitative approach, of the professional profiles associated with the support of people with experiences of "social detachment" (Paugam, 2000). The answers at the level of specific training of these professionals do not follow the trend of structuring of the sector. The results presented point towards the complexity and demand of the professional profile that we call "Insertion Professional", whose intervention takes place in a sector with multiproblems, in which there is a lack of guidance on the definition of their functions and in which there is an evidence of empathic relationship competencies with the target publics of the interventions.

KEYWORLDS: Social economy; professional profiles; social insertion; professionalization 
SUMÁRIO: 1. INTRODUÇÃO. 2. EMERGÊNCIA E RECONHECIMENTO DO PERFIL PROFISSIONAL DE AGENTE DE INSERÇÃO. 3. A ECONOMIA SOCIAL ENQUANTO LUGAR PRIVILEGIADO PARA A EMERGÊNCIA E RECONHECIMENTO DO PERFIL PROFISSIONAL DE AGENTE DE INSERÇÃO. 4. ABORDAGEM METODOLÓGICA. 5. RESULTADOS PRELIMINARES. 5.1. Agente de Inserção: um perfil profissional complexo. 5.2. Desafios ao nível da profissionalização. 6. CONSIDERAÇÕES FINAIS. 7. REFERÊNCIAS BIBLIOGRÁFICAS.

SUMMARY: 1 . INTRODUCTION. 2. EMERGENCE AND RECOGNITION OF THE PROFESSIONAL PROFILE OF EMPLOYMENT PLACEMENT AGENTS. 3. THE SOCIAL ECONOMY AS A PRIVILEGED PLACE FOR THE EMERGENCE AND RECOGNITION OF THE PROFESSIONAL PROFILE OF THE INSERTION AGENT. 4. METHODOLOGICAL APPROACH. 5. PRELIMINARY RESULTS. 5.1. Insertion Agent: a complex professional profile. 5.2. Challenges at the level of professionalization. 6. FINAL CONSIDERATIONS. 7. BIBLIOGRAPHICAL REFERENCES.

\section{INTRODUÇÃO}

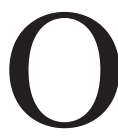
objetivo do presente artigo consiste em analisar o perfil profissional dos técnicos que, inseridos em organizações da economia social, intervêm no sentido de promover o envolvimento de pessoas em situação de vulnerabilidade em processos de capacitação que têm em vista a sua inserção social. Partimos do conceito de perfis profissionais, enquanto um objeto de estudo em permanente reflexão pela Sociologia, em particular pela Sociologia do Trabalho e pela Sociologia das Profissões ${ }^{1}$. Interessa-nos analisar o processo de reconhecimento do perfil profissional que designamos de "Agente de Inserção".

Estes profissionais dedicam-se a funções relacionadas com o acompanhamento de pessoas em situação de vulnerabilidade para uma integração social. A etimologia da palavra acompanhamento remete para a ideia de "estar", "ficar com", "junto a", "ir na mesma direção". Assim, o profissional que acompanha pessoas em situação de desvantagem é aquele que está ao seu lado, que percorre um caminho junto de, sendo este um dos fundamentos da atividade profissional ${ }^{2}$. A categoria de classificação dos públicos com os quais e para os quais trabalham encerra múltiplas subcategorias, assumindo um caráter polissémico. Com efeito, enquanto fenómeno

\footnotetext{
1 RODRIGUES, M.L., Sociologia das Profissões, Celta Editora: Oeiras, 1997. DUBAR, C., A socialização: construção das identidades sociais e profissionais, São Paulo: Martins Fontes, 2005. GONÇALVES, C., "Análise sociológica das profissões: principais eixos de desenvolvimento", Revista da Faculdade de Letras: Sociologia, pp.177-223, 2008.

2 PAUL, M., La démarche d'accompagnement. Repères méthodologique et ressources théoriques. Deboeck supérieur, Louvain-la-Neuve, 2020.
} 
complexo, a vulnerabilidade pode afetar grupos sociais que na sequência da sua condição de exclusão não beneficiam de direitos sociais, por inibição, por desconhecimento da sua existência e/ou sobre a forma de acesso, bem como pela complexidade associada aos processos de requisição. Trata-se de um conceito polissémico utilizado em diversas disciplinas científicas ${ }^{3}$ que não pode ser reduzido a simples categorizações institucionais e administrativas. Não raras vezes, esta simplificação traduz um conjunto de traços estereotipados que não têm em conta a diversidade de fatores identitários e de vivências de cada pessoa ${ }^{4}$. A vulnerabilidade também pode constituir uma condição relativa aos indivíduos que se encontram inseridos no mercado de trabalho e que estão sujeitos a situações de precaridade laboral e baixos salários. No entanto, como afirma Marques et. al (2016) os indivíduos que exercem uma ocupação laboral apresentam menor risco de desvantagem social.

Além do acesso a direitos sociais e condição perante o trabalho, a idade é também considerada uma variável explicativa do grau de vulnerabilidade dos indivíduos e dos grupos sociais. Acresce ser sempre necessário considerar outras variáveis nomeadamente a rede de apoio social, a dinâmica familiar, os recursos materiais, o rendimento e o nível de escolaridade. Os grupos que se encontram em situação de vulnerabilidade são aqueles que estão expostos a novos riscos sociais como crianças, jovens, mulheres trabalhadoras, pessoas de minorias étnicas e raciais, famílias com crianças pequenas e pessoas com competências reduzidas ou que não se enquadram no novo paradigma laboral ${ }^{6}$. O conceito de vulnerabilidade é utilizado em diferentes disciplinas científicas, pelo Estado e pelos profissionais que trabalham no setor da ação social, por exemplo, e cujo significado embora tenha sido problematizado por autores como os mencionados anteriormente, carece de estabilidade e consenso ao nível dos indicadores que concorrem para a sua classificação. Contribui para esta situação o facto de a vulnerabilidade ser mutável no tempo e no espaço, por um lado, e estar dependente do cruzamento de diferentes variáveis, que não se excluem entre si, por outro.

É nesta perspetiva que os contributos da teoria da interseccionalidade se revela tão pertinente para os contextos de investigação e intervenção em análise, justamente para enformar as interações entre relações das diferentes categorias master que são o sexo/género, a classe, a etnicidade, a religião, a nacionalidade, a

\footnotetext{
3 Alwang, J.; Siegel, P. \& Jorgensen, S., "Vulnerability as Viewed from Different Disciplines", World Bank Document, SP Discussion Paper, 0115, 2001.

4 LIMA, L. \& TROMBET, C., Le travail de Conseiller en Insertion, Montrouge, ESF Éditeurs, (2017).

5 Marques, A. P.,"Repensar o mercado de trabalho: emprego Vs desemprego", Sociologia e Cultura 1. Cadernos do Noreste, Série Sociologia, Vol. 13 (1) 133-155, 2000.

6 ZIMMERMANN, A. , "Social Vulnerability as an Analytical Perspective", Social Vulnerability as an Analytical Perspective, Discussion Paper No. 4., 2017.
} 
orientação sexual e a deficiência ${ }^{7}$ para compreender os processos de desinserção social. A teoria da interseccionalidade começou por ser desenvolvida pelos estudos afro-americanos e pelas feministas negras nos anos $1980^{8}$. Foi então estabelecida uma relação entre a identidade de mulher e a identidade afro-americana para compreender e descrever a situação de dominação das mulheres negras. Naturalmente que a abordagem interseccional não atende ao conjunto dos percursos de vida individuais, todavia permite trazer, do ponto de vista teórico e da intervenção, contributos que integram a diversidade de vivências e as nuances próprias às diversas problemáticas em análise, tratando-se assim de uma abordagem ora holística ora específica? .

Apesar das diferenças, estas categorias apresentam alguns aspetos em comum, relacionadas quer com características formais /tangíveis - como a idade, o sexo, o grau de incapacidade, a situação familiar, entre outras - referentes a critérios de elegibilidade de acesso aos mecanismos de políticas sociais e de emprego, quer intangíveis associadas a percursos de vida marcados por fenómenos de "desqualificação social"10 designadamente através de "trajetórias de emprego em carrossel""

As temáticas da integração social e socio-laboral são complexas, pelo que exigem a ação integrada de diversas dimensões de inclusão social. Existem inúmeros modelos por toda a Europa, os quais procuram desenvolver soluções para os problemas que os públicos em situação de vulnerabilidade enfrentam, em particular as pessoas em situação de desempego de longa duração, cujo afastamento em relação ao trabalho está associado a fatores sociais e educacionais, e, não raras vezes, a doenças físicas e psicológicas. Assim, e apesar de assumirem formas heterógenas, podemos identificar estas soluções na categoria das WISE - Work Integration Social Entreprises. Tratam-se de negócios sociais de produção e comercialização de bem e serviços, distinguem-se de outro tipo de empresas pela sua missão social integrar pessoas que estão afastadas do mercado de trabalho, quer por baixos recursos educacionais, quer por trajetórias de desemprego de longa duração ou também por incapacidades físicas e/ou mentais ${ }^{12}$.

7 NOGUEIRA, C., Interseccionalidade e psicologia feminista, BA- Brasil, Editora Devires, 2017.

8 NOGUEIRA, C., Interseccionalidade e psicologia feminista, BA- Brasil, Editora Devires, 2017.

9 DAVID-BELlEMARE, E., WILliAMS, N., Pauvreté et précarité: une approche inspirée de l'intersctionnalité. Centre de santé et de services sociaux Champlain-Charles-Le Moyne, Université de Sherbrooke, n.d. NOGUEIRA, C., Interseccionalidade e psicologia feminista, BA- Brasil, Editora Devires, 2017.

10 PAUGAM, S., A desqualificação social. Ensaio sobre a nova pobreza, Porto: Porto Editora, 2006.

11 DIOGO, F., Pobreza, Trabalho, Identidade, Celta Editora. Lisboa, 2007.

12 QUINTÃO, C., MARTINHO, A. L. \& GOMES, M., "Perfil profissional emergente de coaching para a inserção de públicos em situação de vulnerabilidade", Atas XVII Encontro Nacional SIOT Emprego, desenvolvimento e coesão social, (pp. 255-272) Setúbal: Instituto Politécnico de Setúbal, 
Além da categoria tangível da situação de desemprego de longa duração, realçamos também a categoria de jovens em risco, provenientes de contextos vulneráveis, em abandono escolar precoce, em situação de desocupação e com comportamentos desviantes, para mencionar apenas algumas características. Observam-se igualmente diferentes modelos de intervenção social focados nestes perfis em todo o contexto europeu. Apenas como exemplo realçamos o caso, em Portugal, do Programa Escolhas, uma política pública cujas intervenções sob a forma de projetos têm permitido a capacitação e empoderamento de crianças e jovens ${ }^{13}$; e, em Espanha, as Escolas de Segunda Oportunidade com contributos favoráveis para a formação e construção de trajetórias socioeducativas de integração social de jovens ${ }^{14}$.

A área da inclusão social constitui um objeto específico de intervenção de profissionais das ciências humanas e sociais com perfis de pluriatividade ${ }^{15}$, inseridos em organizações da economia social. Assim, focamos a nossa análise nas práticas profissionais desenvolvidas neste setor, justificado pelo crescente reconhecimento do seu papel enquanto ator-chave na operacionalização das políticas sociais e do emprego ${ }^{16}$.

O paradoxo entre um reconhecimento internacional crescente dos perfis profissionais ligados à inserção social de pessoas em situação de vulnerabilidade ${ }^{17} \mathrm{e}$ a invisibilidade que assume em Portugal, designadamente na Classificação Portuguesa das Profissões ${ }^{18}$, leva-nos a investigar esta área temática e procurar compreender os contornos do exercício desta função.

2017. DAVISTER, C., DEFOURNY \& J. GREGOIRE, O., "Work Integration Social Enterprises in the European Union: An Overview of Existing Models". EMES Working Papers, 4, 2004.

${ }^{13}$ ALEXANDRE, J., BARATA, M. C., OLIVEIRA, S., Almeida, S., \& GOMES, J, : Avaliação externa do Programa Escolhas E7G: Relatório final, Lisboa: ACM, 2000.

14 MORALES, I., La formación en las E2O acreditadas: perfil, trayectoria y condiciones de éxito de las y los jóvenes, Universitat de València, Grupo de Investigación Transicions, 2021.

15 VELOSO, L., "Profissões, mercado de trabalho e organizações: trabalho social e terceiro setor", Trabalho social profissional no Terceiro Setor, Viseu, Psicoma, pp.181-187, 2014.

16 CHAVES, R. \& MONZÓN, J.L. (Dirs.), Best practices in public policies regarding the European Social Economy post the economic crisis, Brussels: European Economic and Social Committee, CIRIEC. DOI: 10.2864/551286, 2018. CHAVES, R.; GALLEGO-BONO; J., "Transformative Policies for the Social and Solidarity Economy: The New Generation of Public Policies Fostering the Social Economy in Order to Achieve Sustainable Development Goals. The European and Spanish Cases", Sustainability 2020, 12, 4059; doi:10.3390/su12104059, 2020. ONU, Satellite Account on Non-profit and Related Institutions and Volunteer Work, Department of Economic and Social Affairs, United Nations publication. INE - Instituto Nacional de Estatística, Inquérito ao Setor da Economia Social - 2018, Instituto Nacional de Estatística, I. P., Lisboa, 2020.

17 ABIÉTAR, M., ROS-GARRIDO, A. \& MARHUENDA, F., "Profesionales de apoyo a la inserción: formación y acompañamiento en empresas de inserción", CIRIEC-España, Revista de Economía Pública, Social y Cooperativa, 94, 155-183, DOI: 10.7203/CIRIEC-E.94.12698, 2018. CASTRA, D., L'insertion professionnelle des publics précaires, Presses Universitaires de France, 2003.

${ }^{18}$ INE - Instituto Nacional de Estatística, Classificação Portuguesa das Profissões, Instituto Nacional de Estatística, I. P., Lisboa. 


\section{Emergência e Reconhecimento do Perfil Profissional de AgEnTE DE InSERÇÃo}

Os perfis profissionais emergentes percorrem um itinerário, não linear, até ao seu reconhecimento formal. Com efeito, os perfis profissionais constituem um objeto de estudo em permanente reflexão pela Sociologia, em particular pela Sociologia do Trabalho e pela Sociologia das Profissões ${ }^{19}$. Assim, o objetivo de privilegiar neste texto a questão dos perfis profissionais assenta, antes de mais, na intenção de mostrar que o reconhecimento de um determinado perfil profissional tem repercussões na visibilidade do trabalho desenvolvido por um conjunto de pessoas, bem como da oferta formativa inerente ao desempenho das especificidades desse mesmo perfil.

Os fenómenos ligados às profissões têm sido amplamente estudados a nível internacional, desde as primeiras décadas do século XX. Esta análise tem-se intensificado em contexto europeu e nacional, desde a década de 1990. Em Portugal, autores como Rodrigues e Gonçalves ${ }^{20}$ analisam em detalhe a evolução do conceito, através das principais correntes sociológicas e suas contracorrentes críticas, percorrendo os principais contributos e desafios apresentados por estas. Se atendermos à diversidade de contributos teórico-conceptuais para a análise de um campo tão central como é o campo profissional, podemos ainda assim, e seguindo a sistematização de Rodrigues e Gonçalves ${ }^{21}$, destacar as seguintes características

19 RODRIGUES, M.L., Sociologia das Profissões, Celta Editora: Oeiras, 1997. GONÇALVES, C., "Análise sociológica das profissões: principais eixos de desenvolvimento", Revista da Faculdade de Letras: Sociologia, pp.177-223, 2008. DUBAR, C., A socialização: construção das identidades sociais e profissionais, São Paulo: Martins Fontes, 2005. BOURDIEU, P.; CHAMBOREDON, J. C; PASSERON, J. C., A profissão do sociólogo: preliminares epistemológicas, Petrópolis: Vozes, 1999 GONÇALVES, C., "Análise sociológica das profissões: principais eixos de desenvolvimento", Revista da Faculdade de Letras: Sociologia, pp.177-223, 2008. DUBAR, C., A socialização: construção das identidades sociais e profissionais, São Paulo: Martins Fontes, 2005. BOURDIEU, P.; CHAMBOREDON, J. C; PASSERON, J. C., A profissão do sociólogo: preliminares epistemológicas, Petrópolis: Vozes, 1999.

20 RODRIGUES, M.L., Sociologia das Profissões, Celta Editora: Oeiras, 1997. GONÇALVES, C., "Análise sociológica das profissões: principais eixos de desenvolvimento", Revista da Faculdade de Letras: Sociologia, pp.177-223, 2008. DUBAR, C., A socialização: construção das identidades sociais e profissionais, São Paulo: Martins Fontes, 2005. BOURDIEU, P.; CHAMBOREDON, J. C; PASSERON, J. C., A profissão do sociólogo: preliminares epistemológicas, Petrópolis: Vozes, 1999. GONÇALVES, C., "Análise sociológica das profissões: principais eixos de desenvolvimento", Revista da Faculdade de Letras: Sociologia, pp.177-223, 2008. DUBAR, C., A socialização: construção das identidades sociais e profissionais, São Paulo: Martins Fontes, 2005. BOURDIEU, P.; CHAMBOREDON, J. C; PASSERON, J. C., A profissão do sociólogo: preliminares epistemológicas, Petrópolis: Vozes, 1999. GONÇALVES, C., "Análise sociológica das profissões: principais eixos de desenvolvimento", Revista da Faculdade de Letras: Sociologia, pp.177-223, 2008.

${ }^{21}$ RODRIGUES, M.L., Sociologia das Profissões, Celta Editora: Oeiras, 1997. GONÇALVES, C., "Análise sociológica das profissões: principais eixos de desenvolvimento", Revista da Faculdade de Letras: Sociologia, pp.177-223, 2008. DUBAR, C., A socialização: construção das identidades sociais e profissionais, São Paulo: Martins Fontes, 2005. BOURDIEU, P.; CHAMBOREDON, J. C; 
associadas à constituição de uma profissão: i) uma especialização de serviços; ii) a criação de associações profissionais, que fixam os padrões atitudinais, consubstanciados em códigos deontológicos para o exercício da profissão; iii) uma oferta formativa fundada sobre um quadro teórico-concetual específico da área. Este conhecimento específico constitui um elemento-chave na construção do poder e legitimidade da atividade profissional, estabelecendo a distinção entre o exercício desta atividade comparativamente a uma que é amadora ${ }^{22}$.

Interessa-se particularmente a relação e, de certa forma, o paradoxo inerente, entre a crescente aceleração das transformações sociais com impacte no mundo laboral e os processos - morosos e políticos -, de reconhecimento de uma profissão. Com efeito, a par de uma tendência de complexificação do mercado de trabalho pautado pelo aumento significativo e, praticamente, constante de novas e especializadas profissões, os processos formais de reconhecimento dos perfis profissionais emergentes tendem a manter um formalismo procedimental, que desafia os tempos modernos de constante transformação. Neste sentido, Gonçalves ${ }^{23}$ também analisa a problemática das novas formas de regulação profissional, enquanto objeto de estudo da Sociologia das Profissões.

A nível internacional, são vários os autores ${ }^{24}$ que reconhecem, por um lado a existência de um perfil profissional específico ligado à área da inserção social de pessoas em situação de vulnerabilidade, e por outro lado, da necessidade de profissionalização do acompanhamento dos grupos-alvo, das políticas sociais e de emprego.

A pertinência deste objeto justifica-se pela sua dependência face a variáveis contextuais, temporais e setoriais, que exigem uma análise contínua e longitudinal, como aliás acontece com vários Observatórios nacionais e internacionais.

PASSERON, J. C., A profissão do sociólogo: preliminares epistemológicas, Petrópolis: Vozes, 1999. GONÇALVES, C., "Análise sociológica das profissões: principais eixos de desenvolvimento", Revista da Faculdade de Letras: Sociologia, pp.177-223, 2008. DUBAR, C., A socialização: construção das identidades sociais e profissionais, São Paulo: Martins Fontes, 2005. BOURDIEU, P.; CHAMBOREDON, J. C; PASSERON, J. C., A profissão do sociólogo: preliminares epistemológicas, Petrópolis: Vozes, 1999. GONÇALVES, C., "Análise sociológica das profissões: principais eixos de desenvolvimento", Revista da Faculdade de Letras: Sociologia, pp.177-223, 2008.

22 RODRIGUES, M.L., Sociologia das Profissões, Celta Editora: Oeiras, 1997. GONÇALVES, C., "Análise sociológica das profissões: principais eixos de desenvolvimento", Revista da Faculdade de Letras: Sociologia, pp.177-223, 2008. DUBAR, C., A socialização: construção das identidades sociais e profissionais, São Paulo: Martins Fontes, 2005. BOURDIEU, P.; CHAMBOREDON, J. C; PASSERON, J. C., A profissão do sociólogo: preliminares epistemológicas, Petrópolis: Vozes, 1999.

23 GONÇALVES, C., "Análise sociológica das profissões: principais eixos de desenvolvimento", Revista da Faculdade de Letras: Sociologia, pp.177-223, 2008.

${ }^{24}$ CASTRA, D., L'insertion professionnelle des publics précaires, Presses Universitaires de France, 2003. ABIÉTAR, M., ROS-GARRIDO, A. \& MARHUENDA, F., "Profesionales de apoyo a la inserción: formación y acompañamiento en empresas de inserción”, CIRIEC-España, Revista de Economía. LIMA, L. \& TROMBET, C., Le travail de Conseiller en Insertion, Montrouge, ESF Éditeurs, (2017). 
Apesar do setor da inserção profissional se ter vindo a consolidar a nível europeu, as respostas ao nível da formação específica para profissionais que nele intervêm não acompanham a tendência de estruturação do setor ${ }^{25}$. Em França, nos anos 80 do século XX, as profissões da inserção procuram diferenciar-se do trabalho social clássico, criticado pelo seu caráter assistencialista e pouco eficaz na efetiva inclusão social e socio-laboral das pessoas acompanhadas. Desde então, tem-se verificado uma crescente profissionalização da área, consubstanciada num conjunto de medidas, tais como a construção de referenciais profissionais, a organização de oferta formativa específica e a homologação dos títulos profissionais associados $^{26}$. A título ilustrativo, observa-se a consolidação desta profissionalização com o reconhecimento formal de profissões e especialização tais como o "Encadrant technique d'insertion", "Chargé d'accompagnement social/professionnel", "Coordonnateur de projet collectif en insertion", "Conseiller en insertion”. Estas profissões encontram-se enquadradas pelo repertório francês das certificações profissionais, conforme o exemplo da profissão, com nível de qualificação 4, de "Encadrant technique d'insertion".

A exigência deste perfil profissional é reconhecida por vários autores ${ }^{27}$ pelo seu caráter complexo e pela variedade de conhecimento e de tarefas inerentes. Castra $^{28}$ identifica a necessidade de conhecimento aprofundado e específico, quer das políticas sociais, quer da rede de organizações de apoio dirigidas à inserção profissional (e que podem intervir na área social, da saúde, habitação, etc.), quer ainda do funcionamento do mercado de trabalho, dos empregos e das profissões.

Em Portugal, verifica-se uma ausência de reconhecimento de perfis profissionais específicos para o trabalho de acompanhamento de pessoas em situação de vulnerabilidade. A não existência de tal profissão implica, por um lado, uma não definição de funções e responsabilidade específicas e, por outro, a ausência de qualificação inicial específica ou de formação estruturada dirigida a estes profissionais $^{29}$. Esta tendência inscreve-se num contexto nacional em que o este setor continua pouco estruturado, não existindo políticas públicas direcionadas para esta área específica de intervenção. O primeiro grande estudo europeu sobre inser-

25 CASTRA, D., L'insertion professionnelle des publics précaires, Presses Universitaires de France, 2003.

${ }^{26}$ LIMA, L. \& TROMBET, C., Le travail de Conseiller en Insertion, Montrouge, ESF Éditeurs, (2017).

27 PAUL, M., La démarche d'accompagnement. Repères méthodologique et ressources théoriques. Deboeck supérieur, Louvain-la-Neuve, 2020. CASTRA, D., L'insertion professionnelle des publics précaires, Presses Universitaires de France, 2003.

${ }^{28}$ CASTRA, D., L'insertion professionnelle des publics précaires, Presses Universitaires de France, 2003.

29 ASSOCIAÇÃO A3S, "The marketing and coaching functions of work integrated social enterprises (WISE)", An exploratory study in 5 European countries, http://www.evtnetwork.it/wp-content/ uploads/2016/11/IO-1_Exploratorystudy_Final-Version.pdf., 2016. 
ção socio laboral de pessoas em situação de vulnerabilidade data de $1998^{30}$ e não contempla Portugal nos nove países então analisados. De salientar que Portugal apresenta uma situação atípica no contexto europeu, com a Lei das Empresas de Inserção em $1998^{31}$ abolida em 2015 e apesar do forte dinamismo desta tipologia por toda a Europa ${ }^{32}$.

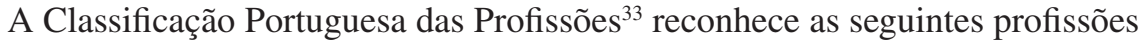
que, apesar de não específicas para o trabalho ao nível da empregabilidade de pessoas em situação de vulnerabilidade, apresentam um perfil que se aproxima desta área profissional: i) Técnico da Área do Emprego; ii) Técnico de Nível Intermédio de Apoio Social; iii) Especialista do trabalho Social e iv) Especialista em Recursos Humanos. Passamos a apresentar, na Figura 1, o descritivo das principais tarefas e funções das profissões. As profissões de Técnico da área do emprego e de Técnico de nível intermédio de apoio social inscrevem-se no grande Grupo 3 dos Técnicos e Profissões de Nível Intermédio, que "compreende as tarefas e funções das profissões técnicas de nível intermédio, com especial incidência nos domínios das ciências físicas, de engenharia, indústria, ciências da vida, saúde, áreas financeira, administrativa, negócios, jurídica, social, desportiva, cultural e tecnologias de informação e comunicação" ${ }^{34}$. As profissões de Especialista do trabalho social e Especialista em Recursos Humanos enquadram-se no grande Grupo 2 dos Especialistas das atividades intelectuais e científicas, que "compreende as tarefas e funções das profissões intelectuais e científicas, com particular incidência nos domínios da investigação, desenvolvimento e aplicação do conhecimento humano (ciências físicas, naturais, sociais e humanas)"35.

\footnotetext{
30 DEFOURNY, J., "Origenes, Contextos y Funciones de un Tercer Gran Sector" in MONZÓN, José Luis; DEFOURNY, Jaques, 1987, "Economía Social. Entre Economía Capitalista y Economía Pública", CIRIEC España, 1987.

${ }^{31}$ Portaria n. $^{\circ} 348-\mathrm{A} / 98$

32 Nyssens, M., Social Enterprise, London / New York: Routledge, 2006. QUINTÃO, C., MARTINHO, A. L. \& GOMES, M., "Perfil profissional emergente de coaching para a inserção de públicos em situação de vulnerabilidade", Atas XVII Encontro Nacional SIOT Emprego, desenvolvimento e coesão social, (pp. 255-272) Setúbal: Instituto Politécnico de Setúbal, 2017. ASSOCIAÇÃO A3S, "The marketing and coaching functions of work integrated social enterprises (WISE)", An exploratory study in 5 European countries, http://www.evtnetwork.it/wp-content/uploads/2016/11/IO-1_Exploratorystudy_Final-Version.pdf., 2016.

${ }^{33}$ INE - Instituto Nacional de Estatística, Classificação Portuguesa das Profissões, Instituto Nacional de Estatística, I. P., Lisboa, 2011, op.cit. pp.191.

${ }^{34}$ INE - Instituto Nacional de Estatística, Classificação Portuguesa das Profissões, Instituto Nacional de Estatística, I. P., Lisboa, 2011, op.cit. pp.191.

35 INE - Instituto Nacional de Estatística, Classificação Portuguesa das Profissões, Instituto Nacional de Estatística, I. P., Lisboa, 2011, op.cit. p.123.
} 
Figura 1. Descritivo de Profissões relacionadas com a área da inserção social e socio laboral de pessoas em situação de vulnerabilidade

\begin{tabular}{|c|c|c|}
\hline Designação & Código & Descritivo funcional \\
\hline $\begin{array}{l}\text { Técnico da Área } \\
\text { do Emprego }\end{array}$ & 3333 & $\begin{array}{c}\text { Combinar a procura com a oferta de emprego } \\
\text { Encontrar trabalhadores para ofertas de emprego, recebendo uma comissão do } \\
\text { empregador ou do trabalhador } \\
\text { Discutir com os empregadores as competências e outras características requeridas } \\
\text { pelos trabalhadores a contratar } \\
\text { Encontrar trabalhadores com competências requeridas e executar as formalidades } \\
\text { de acordo com a legislação nacional ou internacional } \\
\text { Assegurar que os contratos de trabalho cumprem a legislação e assiná-los } \\
\text { Aconselhar e informar sobre programas de formação }\end{array}$ \\
\hline $\begin{array}{l}\text { Técnico de Nível } \\
\text { Intermédio de } \\
\text { Apoio Social }\end{array}$ & 3412 & $\begin{array}{l}\text { Recolher informação das necessidades da pessoa e avaliar qualificações e pontos fortes e fracos } \\
\text { Ajudar pessoas idosas ou com deficieincia no acesso a serviços e melhorar as suas } \\
\text { capacidades para integração na sociedade } \\
\text { Acompanhar pessoas a identificar opções e a desenvolver planos de ação para apoio } \\
\text { e acesso a recursos comunitários (assistência legal, médica, financeira, apoio social, } \\
\text { alojamento, emprego, transporte, cuidados diários, etc.) } \\
\text { Aconselhar pessoas que habitem em prisões e lares de transição, supervisionar e } \\
\text { acompanhar as suas atividades e apoiar nos processos de libertação ou pré libertação } \\
\text { Fornecer serviços de intervenção em situações de crise e proteção de emergência } \\
\text { Colaborar na organização de seminários sobre aquisição de competências, programas } \\
\text { de tratamento de abuso de substâncias nocivas, gestão de comportamentos e outros } \\
\text { programas de serviços comunitários e sociais } \\
\text { Apoiar a avaliação da eficácia das intervenções e programas através da monitorização e } \\
\text { relato dos progressos das pessoas envolvidas }\end{array}$ \\
\hline $\begin{array}{l}\text { Especialista do } \\
\text { Trabalho Social }\end{array}$ & 2635 & $\begin{array}{l}\text { Entrevistar indivíduos, famílias ou grupos para avaliar situações e problemas e } \\
\text { determinar os serviços necessários } \\
\text { Analisar situação dos indivíduos e apresentar alternativas para solução dos problemas } \\
\text { Proporcionar aconselhamento, terapia, serviços de mediação e sessões de grupo para } \\
\text { que o indivíduo desenvolva competências para resolver e lidar com os seus problemas } \\
\text { sociais e pessoais } \\
\text { Planear e implementar programas de intervenção para auxílio de clientes e consultar } \\
\text { serviç̧os que fornecem assistência financeira, ajuda legal, alojamento, tratamento } \\
\text { médico e outros serviços }\end{array}$ \\
\hline $\begin{array}{c}\text { Especialista } \\
\text { em Recursos } \\
\text { Humanos }\end{array}$ & 2423 & 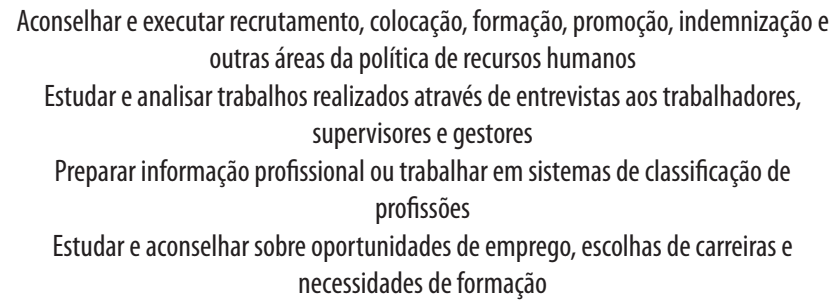 \\
\hline
\end{tabular}

Fonte: Classificação Portuguesa das Profissões (INE, 2011) 
No setor da economia social, a análise dos perfis profissionais não tem acompanhado o crescimento, representatividade e contributos do setor para a economia nacional, enquanto setor empregador e operacionalizador de medidas públicas.

\section{A ECONOMIA SOCIAL ENQUANTO LUGAR PRIVILEGIADO PARA A EMERGÊNCIA E RECONHECIMENTO DO PERFIL PROFISSIONAL DE AgEnTE DE INSERÇÃo}

A economia social tem sido reconhecida politicamente a nível internacional e nacional enquanto motor de desenvolvimento económico e social. A par do seu peso económico, designadamente enquanto agente empregador, o trabalho das organizações que integram o setor da economia social é essencialmente desenvolvido em áreas que constituem grandes desafios do atual mercado de trabalho, com especial destaque para a inserção social e sócio laboral. Num relatório de 2017, a Organização Internacional do Trabalho reconhece o papel das organizações da economia social na resposta efetiva e positiva quer aos desafios de integração pelo trabalho das pessoas em situação de vulnerabilidade, quer às mudanças verificadas no mercado de trabalho, fazendo-o de forma inovadora ${ }^{36}$. A economia social sempre atuou na área do emprego, numa primeira fase devido às dificuldades resultantes da Revolução Industrial, com o associativismo de tipo socioprofissional ligado ao movimento operário, passando pela procura de soluções de autoemprego através do empreendedorismo social dos anos 1990. Atualmente, o setor da Economia Social contribui e pode continuar a contribuir para a execução dos Objetivos de Desenvolvimento Sustentável da Agenda 2030 da Organização das Nações Unidas ${ }^{37}$.

Sendo esta pesquisa realizada em Portugal, interessa-nos particularmente o conceito de economia social, amplamente reconhecido neste território pelos stakeholders. De igual forma, em Portugal há legitimação jurídica do setor, pela aprovação, em 2013, da Lei de Bases da Economia Social. Todavia, tal reconhecimento não constitui garante da implementação de outro tipo de medidas ${ }^{38}$.

\footnotetext{
${ }^{36}$ BORZAGA, C., SALVATORI, G. \& BODINI, R., Social and Solidarity Economy and the Future of Work. Geneva: International Labour Office, 2017.

37 CHAVES, R.; GALLEGO-BONO; J., "Transformative Policies for the Social and Solidarity Economy: The New Generation of Public Policies Fostering the Social Economy in Order to Achieve Sustainable Development Goals. The European and Spanish Cases", Sustainability 2020, 12, 4059; doi:10.3390/su12104059, 2020. ONU, Satellite Account on Non-profit and Related Institutions and Volunteer Work, Department of Economic and Social Affairs, United Nations publication. INE - Instituto Nacional de Estatística, Inquérito ao Setor da Economia Social - 2018, Instituto Nacional de Estatística, I. P., Lisboa, 2020.

38 CHAVES, R. \& MONZÓN, J.L. (Dirs.), Best practices in public policies regarding the European Social Economy post the economic crisis, Brussels: European Economic and Social Committee, CIRIEC. DOI: 10.2864/551286, 2018.
} 
O setor da economia social manifesta um forte pluralismo na forma, modalidades e agentes propulsores da sua ação. Em Portugal, com a implementação da democracia no pós-25 de Abril, é estabelecida uma nova relação de cooperação entre o Estado e as organizações da economia social, designadamente pela atribuição do estatuto de Instituição Particular de Solidariedade Social (IPSS). A partir dessa altura, este setor desenvolveu respostas com grande intensidade face a problemáticas de ação social, muitas vezes resultantes de problemas articulados com o emprego, subemprego ou desemprego.

As organizações da economia social têm contribuído para a dinamização do tecido económico português, mesmo numa conjuntura de crise, quer ao nível do Valor Acrescentado Bruto, quer ao nível de uma maior empregabilidade da população ativa. Trata-se de um setor que representa um motor fundamental para a economia e desenvolvimento do país, com representação de cerca de $6,1 \%$ do total do emprego remunerado, em $2016^{39}$. Especificamente, o setor constitui-se como um "empregador por excelência das pessoas com formação de nível superior no domínio das ciências humanas e sociais" $"$.

Esta outra economia ${ }^{41}$, mais democrática e inclusiva, afirma-se através do seu envolvimento em projetos orientados para a capacitação das comunidades e subsequente melhoria das suas condições de vida. Assumem um papel decisivo na implementação de uma sociedade mais inclusiva e complementam as políticas sociais do Estado de Bem-Estar ${ }^{42}$ no combate aos velhos e novos problemas de pobreza e exclusão social. São frequentemente alvo de financiamento público e privado, não sendo, no entanto, alvo de uma monitorização sistemática da sua ação ${ }^{43}$.

Ao estimular a utilidade social das pessoas, procurando estratégias de empregabilidade inclusiva e de inclusão plena, o setor da economia social adquire gradualmente maior capacidade empregadora e potencial de inclusão dos públicos afastados do mercado de trabalho. O modelo europeu das WISE, com especificidades legais, de abrangência e de atuação nos diferentes países, tem contribuído,

${ }^{39}$ INE - Instituto Nacional de Estatística, Conta Satélite da Economia Social 2016, Instituto Nacional de Estatística, I. P./CASES - Cooperativa António Sérgio para a Economia Social, Lisboa, Lisboa, 2019.

40 VELOSO, L., "Profissões, mercado de trabalho e organizações: trabalho social e terceiro setor", Trabalho social profissional no Terceiro Setor, Viseu, Psicoma, pp.181-187, 2014.

${ }^{41}$ CATTANI, A.; LAVILLE, J.-L.; GAIGER, L. I.; HESPANHA, P. (orgs.), Dicionário internacional da outra economia, Coimbra, Almedina, 2009.

42 DEFOURNY, J., "Origenes, Contextos y Funciones de un Tercer Gran Sector" in MONZÓN, José Luis; DEFOURNY, Jaques, 1987, "Economía Social. Entre Economía Capitalista y Economía Pública", CIRIEC España, 1987.

${ }^{43}$ VELDEN, M.; ALVAREZ, N. (org), A map of social enterprises and their eco-systems in Europe. Country report: Portugal, London: European Commission, 2014. 
com potencial inovador, para a capacitação das pessoas em situação de vulnerabilidade. Suportam o crescimento social e profissional das pessoas a longo prazo, para a saída progressiva da condição desfavorecida ${ }^{44}$.

Não obstante observarem-se passos significativos no conhecimento sobre a organização interna do setor, quer por via da Lei de Bases da Economia Social, quer por via da Conta Satélite da Economia Social (CSES) em relação às tipologias de atividade, às relações com o Estado e o Mercado e à situação laboral dos colaboradores e importância do voluntariado, por exemplo; carece ainda um trabalho de diagnóstico sobre dimensões particulares do setor, em concreto, e no que ao objeto deste estudo diz respeito, acerca do perfil profissional dos seus colaboradores.

Observa-se que o Inquérito ao Setor da Economia Social ${ }^{45}$ procura compreender detalhadamente quem são os dirigentes das diferentes entidades da economia social e coloca questões de coerência e identificação com os valores e princípios chave do setor. Todavia, e no que ao ponto 3 deste documento diz respeito - "Caracterização das pessoas ao serviço no setor da Economia Social"46_, continua a ser omissa a caracterização mais abrangente dos seus colaboradores remunerados além do tipo de contrato de trabalho, tipo de horário, percentagem de colaboradores com nacionalidade estrangeira, bem como proporção de colaboradores com vencimento mínimo mensal garantido.

\section{Abordagem metodológica}

A reflexão e os resultados preliminares apresentados resultam de contributos comuns de duas investigações em curso. O estudo A debruça-se especificamente sobre profissionais de acompanhamento de jovens e o estudo B sobre profissionais de acompanhamento de adultos.

Tendo em consideração a escassez de dados sobre este objeto de estudo, e dado o carácter exploratório destas investigações, privilegiou-se uma abordagem qualitativa assente na combinação de técnicas de recolha de $\operatorname{dados}^{47}$. O seguimento de técnicas combinatórios revela-se fundamental na compreensão das diferentes dimensões que se pretendem estudar. O método qualitativo é, portanto, apro-

\footnotetext{
${ }^{44}$ NYSSENS, M., Social Enterprise, London / New York: Routledge, 2006.

45 INE - Instituto Nacional de Estatística, Inquérito ao Setor da Economia Social - 2018, Coleção de Estudos de Economia Social N. ${ }^{\circ}$ 12, Instituto Nacional de Estatística, I. P./CASES - Cooperativa António Sérgio para a Economia Social, Lisboa, 2020.

46 INE - Instituto Nacional de Estatística, Inquérito ao Setor da Economia Social - 2018, Coleção de Estudos de Economia Social N. ${ }^{\circ}$ 12, Instituto Nacional de Estatística, I. P./CASES - Cooperativa António Sérgio para a Economia Social, Lisboa, 2020.

${ }^{47}$ CRESWELL, J.,'The selection of a research design", In Research Design. Qualitative, quantitative and mixed methods approaches ( ${ }^{\mathrm{a}} \mathrm{ed}$.), London: Sage Publications, 2009. DENZIN, N. K., The Research Act, Englewood Cliffs, N. J., Prentice Hall, 1989.
} 
priado para pesquisas cujo principal propósito consiste na análise de significados, práticas e procedimentos ${ }^{48}$.

Os perfis profissionais analisados situam-se na economia social, tratando-se de profissionais que trabalham em respostas contínuas promovidas por IPSS, projetos com financiamento limitado e em iniciativas comunitárias promovidas pela Sociedade Civil. O trabalho empírico de recolha de dados foi realizado junto de profissionais de organizações da economia social da Área Metropolitana de Lisboa (AML) e da Área Metropolitana do Porto (AMP) territórios da NUT II onde se concentraram mais de $1 / 3$ das organizações da economia social, cerca 34,7\% ${ }^{49}$.

O objetivo geral do que nos propomos partilhar neste artigo é o de investigar o perfil profissional dos técnicos, em Portugal, que acompanham pessoas em situação de vulnerabilidade para uma inserção social. Em ambos os estudos, focamos a análise nas seguintes questões comuns de investigação: i) Como se definem os perfis profissionais dos técnicos que acompanham pessoas em situação de vulnerabilidade social?; ii) É possível afirmar a existência de um perfil profissional de Agente de Inserção? e; iii) Quais os desafios da profissionalização da função?

Os resultados preliminares aqui apresentados, recolhidos entre maio de 2019 e maio de 2021, decorrem de 15 entrevistas semidiretivas, 5 entrevistas a informantes privilegiados e 9 estudos de caso. As entrevistas semidiretivas, enquanto técnica de recolha de informação, materializaram-se em conversas com profissionais com perfis, trajetórias e experiências diferenciadas dentro de organizações da economia social. Foram realizadas 5 entrevistas, num total de 8 entrevistados a especialistas e atores do campo do acompanhamento, orientação e aconselhamento de carreira para a inserção social laboral de pessoas em situação de vulnerabilidade. Enquanto método de investigação, os estudos de caso têm sido utilizados por diversas disciplinas das ciências sociais ao permitir ao investigador "to retain the holistic and meaningful characteristics of real-life events" ${ }^{50}$. Os dados dos estudos de caso foram recolhidos através de diversas técnicas combinadas de observação- nomeadamente aquando da visita aos estudos de caso e da participação em reuniões de trabalho das diferentes equipas -, bem como da consulta de documentos - oficiais como o website da Organização, os seus Estatutos, Documentos de sistematização das atividades desenvolvidas -, para além da análise documental a instrumentos de trabalho utilizados pelos entrevistados no seu trabalho de acompanhamento para a inserção socio laboral. Todavia, o que partilhamos neste

48 HAGUETTE, Teresa, Metodologias Qualitativas na Sociologia, 11. a ed. Rio de Janeiro: Vozes, 1987.

49 INE - Instituto Nacional de Estatística, Inquérito ao Setor da Economia Social - 2018, Instituto Nacional de Estatística, I. P., Lisboa, 2020.

50 YIN, R.K., Case Study Research. Design and Methods, Sage,2009. 
artigo, são os contributos recolhidos por via das entrevistas aos profissionais com funções de acompanhamento de pessoas em situação de vulnerabilidade.

\section{RESUltados PRELIMINARES}

Passamos à apresentação dos resultados preliminares, seguindo as duas grandes dimensões de análise associadas à parte do estudo aqui apresentados: i) o perfil profissional de Agente de Inserção; ii) os desafios da profissionalização da função. Não sendo esta uma categoria existente à priori categorizamos, enquanto grupo profissional, o tipo de funções, responsabilidades e competências dos técnicos de acompanhamento em análise como "Agente de Inserção" ora de jovens ora de adultos. São apresentadas as regularidades encontradas no discurso dos diferentes entrevistados.

\subsection{Agente de Inserção: um perfil profissional complexo}

O perfil sociodemográfico dos Agentes de Inserção entrevistados revela uma predominância de profissionais do sexo feminino na faixa etária dos 30-40 anos. Em termos de qualificações, os Agentes de Inserção têm grau de ensino superior. Trata-se de um perfil profissional complexo e exigente onde predominam as qualificações/ saberes das Ciências Sociais, não havendo, grosso modo, a aquisição de formação específica que se ajuste às responsabilidades desempenhadas. Os entrevistados referem que experienciam um processo que passa pelo exercício das suas responsabilidades (fazer) até ao estabelecimento e consolidação de princípios chave orientadores do seu trabalho (aprender-fazendo). Este processo passa pela pesquisa de boas práticas em que aplicam e testam o nível de ajustamento de diferentes técnicas de acompanhamento.

Em termos de especialização, os entrevistados não identificam nenhuma formação específica para o exercício pelo na função. Todavia são mencionadas algumas formações, ora da responsabilidade do financiador das intervenções, ora de organizações de cúpula do setor, nas áreas dos processos operacionais e de diagnóstico, bem como em metodologias de prevenção e intervenção na área psicossocial. Os Agentes de Inserção trabalham na sua maioria em associações em respostas/projetos sociais com financiamento a termo certo, e apresentam trajetórias profissionais em contexto da economia social e/ou com experiências prévias de trabalho com o público-alvo da intervenção.

Os Agentes de Inserção desempenham primordialmente funções de coordenação, intervenção social, gestão de casos, prospeção e acompanhamento. Acumulam responsabilidades com diferentes graus de complexidade e autonomia (multitasking): "portanto fazemos aqui um bocadinho dum trabalho em várias frentes" (Agente de Inserção de adultos - E1 - Estudo de caso Omega). Este desdobramento em tarefas múltiplas é mais acentuado com o ajustamento da 
intervenção à distância (por telefone, videochamada ou sessões presenciais restritas e agendada) devido à pandemia COVID-19: "É um pouco complicado. É assim quase um todo terreno. As funções passavam por desenho, implementação e avaliação do próprio projeto [...] Há aqui outra questão em análise que é o período pandemia ou o período pré pandemia. Porque são mundos completamente diferentes, não é?" (Agente de Inserção de jovens - E14).

As principais responsabilidades foram categorizadas em quatro áreas, associadas ao ciclo de acompanhamento das pessoas em situação de vulnerabilidade: i) Diagnóstico e definição de plano de acompanhamento; ii) Desenvolvimento de competências; iii) Orientação /aconselhamento vocacional/profissional; iv) Encaminhamento e mediação com diferentes interlocutores.

As competências inerentes ao exercício destas funções podem ser classificadas em três categorias de análise: i) flexibilidade e capacidade de adaptação a diferentes áreas e contextos do acompanhamento; ii) empatia, proximidade e resiliência; iii) conhecimento técnicos de diagnóstico, processos e metodologias de acompanhamento.

No que respeita a primeira categoria de análise, os entrevistados referem a necessidade de "ter um jogo de cintura mais apurado" (Agente de Inserção de adultos - E3 - Estudo de caso Delta). A capacidade de adaptação de diferentes situações e pessoas, implica uma disponibilidade para atender às necessidades em diferentes circunstâncias e horários, "podem recorrer a horas e momentos - estou a falar de noites, estamos a falar de fins-de-semana - em que se calhar nenhum outro técnico ou técnica que trabalha para um outro serviço mais formal os pode atender e ajudar." (Agente de Inserção de jovens - E13). Esta flexibilidade - referida pela maioria dos entrevistados - integra o processo de acompanhamento e é condição determinante para um sentimento de maior confiança nos Agentes de Inserção e no trabalho que estão a desenvolver.

Os Agentes de Inserção são figuras de referências positiva para o público com quem trabalham "tanto que em situações de insatisfação ou de alguma diferença é a mim que vêm recorrer e pedir ajuda ou pedir uma decisão"” (Agente de Inserção de jovens - E02) e enfatizam a importância de uma relação de proximidade para com o grupo alvo de intervenção, isto é, conhecer cada um pelo seu nome, conhecer a sua história de vida, as suas competências, para que seja possível a construção de uma relação empática ao longo de todo o processo de acompanhamento.

Assim, as competências de empatia, proximidade e resiliência são identificadas como essenciais para o desempenho das funções em análise, na medida em que "as pessoas percebem que nós estamos lá para haver aqui este suporte, nós somos realmente umas ferramentas fiáveis” (Agente de Inserção de adultos - E3 - Estudo de caso Delta). A resiliência e resistência à frustração, na medida em 
que "não se vê mudanças a curto prazo, portanto, é preciso fazer um investimento enorme e os resultados começam a ser notórios, se aparecerem, a longo prazo" (Agente de Inserção de adultos - E3 - Estudo de caso Delta) e que é necessário saber perseverar e não desistir face às variadas dificuldades quotidianas "temos que os saber levar [...] às vezes eles não fazem logo bem a primeira vez, temos que ir lá e voltar a explicar, olha isto não está bem feito, olha faz assim ou não então faz desta maneira, não, não continua bem há aqui qualquer coisa que ainda tens que, qualquer coisinha que tens que melhorar. E saber levá-los desta forma e criar a afinidade e a relação de simpatia com eles, que acho que é o fundamental. (Agente de Inserção de adultos - E3 - Estudo de caso Alfa). E o facto de" continuarem muitas vezes, mesmo contra muitos fatores que são de risco, conseguem apresentar aqui uma capacidade de [...] desenvolver na mesma as suas tarefas de ir à escola mesmo quando a família não é o contexto mais propício para desempenhar as tarefas escolares, mas continuam a ir...e muitas das vezes também pelas capacidades que eles nos mostram a relacionar connosco com os adultos e com os técnicos da equipa. O facto de conseguirem aqui criar uma relação connosco mesmo quando existem adultos na vida deles que não o conseguem." (Agente de Inserção de jovens - E12)

A última categoria respeita a competências mais técnicas, associadas aos conhecimentos de diagnósticos, bem como aos processos e metodologias de acompanhamentos do público-alvo. Esta categoria é sobretudo identificada pelos Agentes de Inserção que acompanham adultos. São identificadas competências ao nível do domínio das metodologias de educação não formal "eu por exemplo costumo utilizar um sol, "olhem isto é o vosso sol, vocês estão aqui no meio, e vais identificar na parte de cima do sol, nos raios de cima, os aspetos positivos ou as coisas que correram bem na escola durante o $1^{\circ}$ período e em baixo vais colocar as coisas que não correram tão bem [...] utilizo o sol para várias coisas" (Agente de Inserção de jovens - E14) ou "no corpo a corpo, no olho a olho, sobretudo a partir desta prática de utilização de instrumentos musicais" (Agente de Inserção de jovens - E08). Em simultâneo, são referidas competências que têm que ver com o conhecimento do funcionamento do mercado de trabalho e do tecido empregador local "tentar conhecer e tentar com o tecido empresarial aqui da nossa freguesia [...], poder com eles também aqui haver a possibilidade de novas ofertas de emprego e novos postos de trabalho" (Agente de Inserção de adultos - E1 - Estudo de caso Omega).

Face ao exposto, podemos afirmar a tendência de emergência e consolidação de um perfil profissional de Agente de Inserção, pela regularidade de respostas em termos de qualificação, experiência, responsabilidades e competências para o desempenho da função. Com efeito, coorresponde a uma atividade profissional e não a uma atividade amadora. Revela grande complexidade e apresenta caraterísticas diferenciadoras de outros perfis profissionais já reconhecidos, quer pelo tipo de 
públicos e contextos de intervenção, quer pelas competências socio emocionais necessárias para o exercício da função, e dos conhecimentos técnicos e metodológicos dos ciclos de projetos e de processos de acompanhamento.

Apesar das competências socio emocionais identificadas para o exercício da função, tais como a empatia, a resiliência, a flexibilidade e a capacidade de adaptação constituírem competências transversais para o desempenho de grande parte das profissões da atualidade ${ }^{51}$, verificamos que assume um lugar central no desempenho da função de Agente de Inserção. Com efeito, apesar das competências serem partilhadas por uma variedade de outros perfis profissionais, os estudos em análise revestem-se de um carácter específico profundamente correlacionado com o fenómeno complexo das múltiplas vulnerabilidades vivenciadas pelo públicoalvo que o Agente de Inserção acompanha.

Na figura 2, procuramos representar o perfil profissional do Agente de Inserção, em termos da formação para o exercício da função, da experiência anterior, das principais responsabilidades e das principais competências necessárias.

Figura 2. Perfil profissional do Agente de Inserção

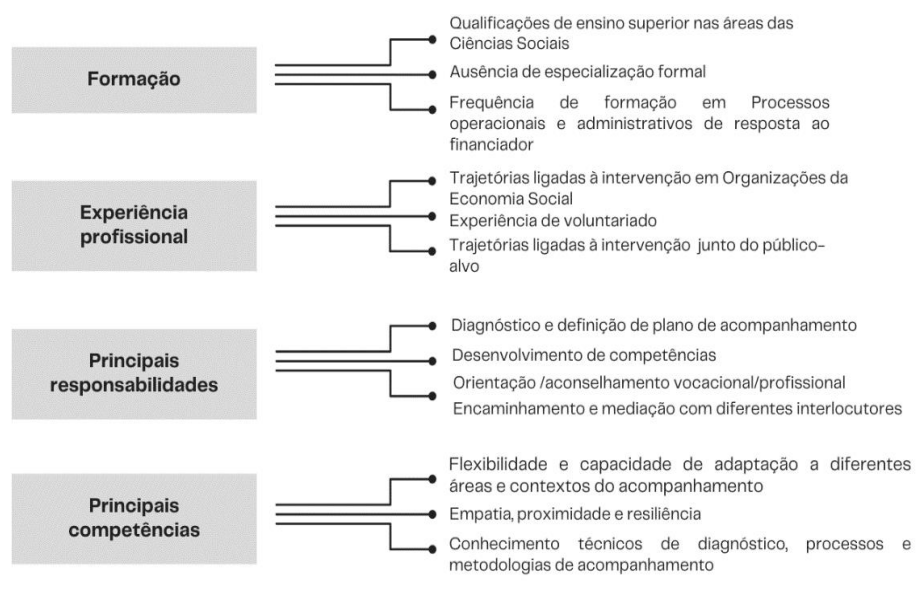

${ }^{51}$ EUROPEAN COMMISSION, Communication from the Commission to the European Parliament, the Council, the European Economic and Social Committee and the Committee of the Regions a New Skills Agenda for Europe. Working together to strengthen human capital, employability and competitiveness, 2016. WORLD ECONOMIC FORUM, The Future of Jobs Report 2020. Geneva- Switzerland, World Economic Forum, 2020. 


\subsection{Desafios ao nível da profissionalização}

De seguida apresentamos os resultados parciais sobre os desafios de profissionalização da atividade de Agente de Inserção. Os resultados focam-se nas entrevistas realizadas junto de Agentes de Inserção e de informantes privilegiados. Os resultados foram categorizados a partir de duas dimensões de análise associadas aos desafios e à profissionalização da função, a saber: i) a complexidade da função e ii) a ausência de formação específica ajustada aos contextos de intervenção.

No que respeita à primeira categoria de análise, verificamos que a função de acompanhamento de pessoas em situação de vulnerabilidade é complexa e implica o domínio de competências específicas. Os entrevistados reconhecem lacunas na sua formação de base para o desempenho desta função que requer competências diversificadas, entre elas, de diagnóstico psicossocial dos públicos em situação de vulnerabilidade, por um lado, e de construção e aplicação de instrumentos de monitorização de resultados, por outro. Estes últimos saberes estão cada vez mais presentes nas condições de financiamento das intervenções, e foram recorrentemente referidos pelos Agentes de Inserção de jovens, ora vejamos:

"Uma das coisas que eu noto mais dificuldades é principalmente nas questões mais académicas. Como é que um profissional da área social e que pode não ter competências em outras áreas, pode perceber a nível cognitivo, se a criança tem efetivamente algum distúrbio? Vai impedir que a aprendizagem seja eficaz...não sei...claro que seria ideal, mas é um bocadinho "cada macaco no seu galho". Até que ponto as equipas estão fortes o suficiente para conseguir avaliar todas as áreas de forma eficaz?" [Agente de inserção de jovens - E3]

“Também nos falta muito as componentes técnicas para conseguir avaliar [...] acabamos muitas vezes por os projetos sentirem-se [...] incapacitados de criar os próprios instrumentos. E quando os criam não têm muita profundidade nos mesmos [...] Acaba por ser tudo assim um pouco em cima do joelho, diria. Mas muito de coração. [Agente de inserção de jovens - E14]

"Portanto, fica um bocadinho a avançar ou a executar no desconhecido...digamos assim. Claramente por falta de tempo, por falta de estratégias para a realização, as grelhas de observação e isso tudo. Nós não temos isso. Desconhecimento dos técnicos sobre como avaliar." [Agente de inserção de jovens- E6]

A segunda categoria de análise, refere-se às incipientes orientações específicas para o desempenho da função, sendo identificado pelos entrevistados que a aprendizagem se faz através da experiência "Nós vamos aprendendo com experiência [...] depois a gente vai aplicar [...] os nossos conhecimentos e [...] vamos deli- 
neando mesmo ao nível de instrumentos de trabalho, de documentos, que vamos adaptando, elaborando" [Agente de inserção de adultos - E3 - Estudo de caso Kapa]. Os entrevistados não se sentem suficientemente orientados no trabalho desenvolvido e nos instrumentos produzidos "Não há uma validação do instrumento que usamos. É um instrumento que nós criamos e que está em constante adaptação tendo em conta aquilo que fazemos. Não sei se é válido. Não está validado de todo. Por vezes temos grandes dúvidas se é aquele instrumento o instrumento certo. Mas quando procurarmos uma resposta também neste sentido de avaliação para avaliar o trabalho que fazemos, não encontramos" [Agente de inserção de jovens - E2]. Face a estas dificuldades, alguns profissionais procuram respostas, ainda que não sendo à medida das suas necessidades, constituem uma orientação para o desempenho da função: "A primeira coisa que eu fiz depois de decidirmos que eu estaria trabalhar mais a empregabilidade foi ir à cidade das profissões e ver os Workshops que lá existem e tenho estado a participar em alguns, pronto, que apesar de serem muito direcionado para quem está a procura de emprego eu acabo por recolher ali um conjunto de indicações que me ajudam depois também a dar indicações para tudo que é orientação, ou seja, não é se calhar a formação mais adequada porque não estão a ser trabalhadas ali as competências dos técnicos, mas é, pronto, dentro daquilo que me está mais próximo neste momento, onde eu consigo ir beber aqui alguma experiência [...] pronto, eu sinto muito essa necessidade. Porque acaba as vezes, por ser um trabalho também muito baseado na nossa experiência laboral, não é, pronto, um bocadinho isso e para este público em concreto" [Agente de inserção de adultos - E2 - Estudo de caso Delta].

Constatamos, de acordo com estes resultados preliminares, que não existe uma formação específica ajustada aos contextos de intervenção, ao contrário do que acontece noutras realidades internacionais: "Há países que têm efetivamente mestrados ou pós-graduações ou inclusive sociedades de profissionais e associações profissionais que proporcionam formação especializada, ou pósgraduações ou mestrados ou mesmo doutoramento, em que efetivamente o foco de intervenção é o aconselhamento. Depois há países, como o nosso caso, em que nós não temos, ainda não temos o desenvolvimento, temos alguns lives, não é? Mas não temos a profissão com um grau de desenvolvimento tão consolidado como por exemplo o Reino Unido e a Irlanda, não é?" [Informante privilegiado 2 da área do counseling]. 


\section{Considerações Finais}

Neste artigo examinamos o perfil profissional dos técnicos, em Portugal, que acompanham pessoas em situação de vulnerabilidade para uma inserção social e socio laboral.

Em resposta à primeira pergunta de investigação que procurava perceber como se definem os perfis profissionais dos técnicos que acompanham pessoas em situação de vulnerabilidade, podemos afirmar que o perfil profissional de Agente de Inserção é complexo e exigente, desde já porque intervém num setor marcado por multiproblemáticas, com recurso a políticas escassas e limitadoras do acompanhamento, mas também porque tem de recorrer a várias áreas profissionais, da intervenção social, dos recursos humanos, do coaching, e a competências de escuta, de disponibilidade, de abertura, de inovação, de resiliência, para citar apenas as mais evidentes. Assim, constamos que se trata de um perfil de competências complexo e que revela pluriatividade, à imagem do que sucede com outros perfis profissionais $^{52}$.

Todavia, é notório que tal complexidade se reveste de uma dimensão adicional quando é necessário o profissional adaptar-se a situações de múltiplas vulnerabilidades das pessoas acompanhadas. Com efeito, estes grupos apresentam características específicas e interseccionais, sendo necessárias abordagens, conhecimentos e instrumentos de trabalho específicos para atender à complexidade dos fenómenos vivenciados e para propor planos de ação individualizados e ajustados a cada pessoa acompanhada.

De acordo com os resultados preliminares apresentados, e respondendo à segunda pergunta de investigação, consideramos ser possível afirmar a existência de um perfil profissional de Agente de Inserção. A análise efetuada à Classificação Portuguesa das Profissões ${ }^{53}$ evidenciou o reconhecimento de profissões que relevam descritivos funcionais que se aproximam ao perfil profissional de Agente de Inserção, nomeadamente a Técnico da área do emprego, Técnico de nível intermédio de apoio social e Especialista em Recursos Humanos. Porém, e após a análise dos resultados preliminares dos dois estudos qualitativos nos quais se realizou 15 entrevistas semidiretivas a profissionais de acompanhamento, 5 entrevistas a informantes privilegiados e 8 estudos de caso, constatamos que estas categorias profissionais não exemplificam e também não certificam a natureza e conteúdo do trabalho realizados pelos Agentes de Inserção.

52 VELOSO, L., "Profissões, mercado de trabalho e organizações: trabalho social e terceiro setor", Trabalho social profissional no Terceiro Setor, Viseu, Psicoma, pp.181-187, 2014.

53 INE - Instituto Nacional de Estatística, Classificação Portuguesa das Profissões, Instituto Nacional de Estatística, I. P., Lisboa, 2011 
Apesar de algumas das principais responsabilidades poderem ser partilhadas com as profissões de Técnico de Nível Intermédio de Apoio Social e de Especialista do Trabalho Social, como é o caso das atividades de encaminhamento para outros serviços, desenho de planos de ação ou ainda promoção de sessões individuais e coletivas, verificamos que a dimensão da empregabilidade está ausente destes descritivos profissionais. No que respeita às profissões de Técnico da Área do Emprego e de Especialista em Recursos Humanos, são mencionadas responsabilidades como a definição do perfil do candidato, o matching entre oferta e procura, ou ainda o aconselhamento para oportunidades de emprego, todavia sem atender à dimensão social associadas à integração laboral. Por um lado, as profissões sociais não integram a dimensão profissional do trabalho desenvolvido pelos Agentes de Inserção e, por outro, as profissões ligadas aos Recursos Humanos não integram a dimensão social correspondente ao perfil de Agente de inserção. Assim, podemos afirmar que as profissões existentes não dão conta da complexidade da função de acompanhamento de pessoas em situação de vulnerabilidade para a sua inserção socio laboral.

Nos casos analisados, e no que aos desafios sobre o nível da profissionalização da função dizem respeito, constatam-se perfis profissionais e estratégias de inserção heterogéneos, uma tendência de adaptação ao contexto e aos seus públicos. No entanto, a sistematização destes perfis e estratégias é fundamental para a experimentação e replicação contextual destes perfis emergentes, no sentido da promoção e reconhecimento destas práticas.

Como pistas de investigação futuras, ressalvamos a importância de alargar o estudo a mais profissionais, por forma a robustecer a amostra. Seria importante analisar as singularidades associadas a diferentes contextos de intervenção, junto de diferentes públicos-alvo. Seguir-se-á uma fase de validação do perfil profissional identificado nos estudos junto dos profissionais auscultados, por forma a aprofundar as suas dimensões e especificidades.

\section{REFERÊNCIAS BIBLIOGRÁFICAS}

ABIÉTAR, M., ROS-GARRIDO, A. \& MARHUENDA, F. (2018): "Profesionales de apoyo a la inserción: formación y acompañamiento en empresas de inserción", CIRIECEspaña, Revista de Economía Pública, Social y Cooperativa, 94, 155-183, DOI: 10.7203/ CIRIEC-E.94.12698.

Alexandre, J., Barata, M. C., Oliveira, S., Almeida, S., \& Gomes, J. (2020): Avaliação externa do Programa Escolhas E7G: Relatório final, Lisboa: ACM.

Alwang, J.; Siegel, P. \& Jorgensen, S. (2001): "Vulnerability as Viewed from Different Disciplines", World Bank Document, SP Discussion Paper, 0115.

ASSOCIAÇÃO A3S. (2016): The marketing and coaching functions of work integrated social enterprises (WISE). An exploratory study in 5 European countries, http://www.evtnetwork. it/wp-content/uploads/2016/11/IO-1_Exploratorystudy_Final-Version.pdf. 
BORZAGA, C., SALVATORI, G. \& BODINI, R. (2017). Social and Solidarity Economy and the Future of Work. Geneva: International Labour Office.

BOURDIEU, P.; CHAMBOREDON, J. C; PASSERON, J. C (1999): A profissão do sociólogo: preliminares epistemológicas. Petrópolis: Vozes, 1999.

CALADO, A., ESTEVÃO, P. \& CAPUCHA, L. (2018). Crise e pobreza em Portugal: resiliência ou proteção social. In Carmo, R., Sebastião, J., Azevedo, J., Martins, S.,

CASTRA, D. (2003): L'insertion professionnelle des publics précaires, Presses Universitaires de France.

CATTANI, A.; LAVILLE, J.-L.; GAIGER, L. I.; HESPANHA, P. (orgs.) (2009): Dicionário internacional da outra economia, Coimbra, Almedina.

CHAVES, R. \& MONZÓN, J.L. (Dirs.) (2018): Best practices in public policies regarding the European Social Economy post the economic crisis, Brussels: European Economic and Social Committee, CIRIEC. DOI: 10.2864/551286.

CHAVES, R.; GALLEGO-BONO; J. (2020): “Transformative Policies for the Social and Solidarity Economy: The New Generation of Public Policies Fostering the Social Economy in Order to Achieve Sustainable Development Goals. The European and Spanish Cases", Sustainability 2020, 12, 4059; doi:10.3390/su12104059.

CIRIEC - INTERNACIONAL (2017). Recent Evolutions of the Social Economy in the European Union. Belgium: European Economic and Social Committee.

CRESWELL, J. (2009): 'The selection of a research design”, In Research Design. Qualitative, quantitative and mixed methods approaches ( $3^{\mathrm{a}} \mathrm{ed}$.). London: Sage Publications.

DAVID-BELLEMARE, E., WILLIAMS, N. (n.d.). Pauvreté et précarité: une approche inspirée de l'intersctionnalité. Centre de santé et de services sociaux Champlain-Charles-Le Moyne, Université de Sherbrooke.

DAVISTER, C., DEFOURNY \& J. GREGOIRE, O. (2014). "Work Integration Social Enterprises in the European Union: An Overview of Existing Models". EMES Working Papers, 4. Disponível: https://ec.europa.eu/commission/sites/beta-political/files/reflectionpaper-social-dimension-europe_en.pdf

DEFOURNY, J. (1987): “Origenes, Contextos y Funciones de un Tercer Gran Sector” in MONZÓN, José Luis; DEFOURNY, Jaques, 1987, "Economía Social. Entre Economía Capitalista y Economía Pública”, CIRIEC España.

DENZIN, N. K. (1989): The Research Act, Englewood Cliffs, N. J., Prentice Hall.

DIOGO, F. (2007): Pobreza, Trabalho, Identidade. Celta Editora. Lisboa.

DUBAR, C. (2005): A socialização: construção das identidades sociais e profissionais, São Paulo: Martins Fontes

EUROPEAN COMMISSION (2015): Guidance Document on Monitoring and Evaluation. Concepts and Recommendations. Disponível em: ps://ec.europa.eu/regional_policy/ sources/docoffic/2014/working/wd_2014_en.pdf

EUROPEAN COMMISSION (2016). Communication from the Commission to the European Parliament, the Council, the European Economic and Social Committee and the Committee of the Regions a New Skills Agenda for Europe. Working together to strengthen human capital, employability and competitiveness. Disponível em: http://eur-lex.europa.eu/legalcontent/EN/TXT/PDF/?uri=CELEX:52016DC0381\&from=EN 
GONÇALVES, C. (2008): "Análise sociológica das profissões: principais eixos de desenvolvimento", Revista da Faculdade de Letras : Sociologia, pp.177-223.

HAGUETTE, Teresa (1987) : Metodologias Qualitativas na Sociologia, 11. a ed. Rio de Janeiro: Vozes. ISBN 978-85-326-08854-3

INE - Instituto Nacional de Estatística, Inquérito ao Setor da Economia Social - 2018 (2020), Inquérito ao Setor da Economia Social - 2018Coleção de Estudos de Economia Social N. ${ }^{\circ} 12$, Instituto Nacional de Estatística, I. P./CASES - Cooperativa António Sérgio para a Economia Social, Lisboa.

INE - Instituto Nacional de Estatística (2019), Conta Satélite da Economia Social 2016, Instituto Nacional de Estatística, I. P./CASES - Cooperativa António Sérgio para a Economia Social, Lisboa, Lisboa.

Lima, L. \& Trombet, C. (2017): Le travail de Conseiller en Insertion. Montrouge, ESF Éditeurs.

Marques, A. P. (2000). Repensar o mercado de trabalho: emprego Vs desemprego. Sociologia e Cultura 1. Cadernos do Noreste, Série Sociologia, Vol. 13 (1) 133-155.

MORALES, I. (2021): La formación en las E2O acreditadas: perfil, trayectoria y condiciones de éxito de las y los jóvenes, Universitat de València, Grupo de Investigación Transicions.

NOGUEIRA, C. (2017): Interseccionalidade e psicologia feminista, BA- Brasil, Editora Devires.

Nyssens, M. (2006): Social Enterprise, London / New York: Routledge.

ONU (2018): Satellite Account on Non-profit and Related Institutions and Volunteer Work, Department of Economic and Social Affairs, United Nations publication, ISBN: 978-921-161643-9.

PAUGAM, S. (2006): A desqualificação social. Ensaio sobre a nova pobreza. Porto: Porto Editora. ISBN 978-972-0-34856-2.

PAUL, M. (2020): La démarche d'accompagnement. Repères méthodologique et ressources théoriques. Deboeck supérieur, Louvain-la-Neuve.

QUINTÃO, C., MARTINHO, A. L. \& GOMES, M. (2017): "Perfil profissional emergente de coaching para a inserção de públicos em situação de vulnerabilidade", Atas XVII Encontro Nacional SIOT Emprego, desenvolvimento e coesão social, (pp. 255-272) Setúbal: Instituto Politécnico de Setúbal.

QUINTÃO, C; MARTINHO, A.L.; GOMES, M. (2018): “As Empresas Sociais de Inserção na Promoção do Emprego e Inclusão Social a Partir de Estudos de Caso Europeus", Gestão e Sociedade, v. 12, n. 32, p. 2349-2366.

RODRIGUES, M.L. (1997). Sociologia das Profissões, Celta Editora: Oeiras

Velden, M.; Alvarez, N. (org). 2014: A map of social enterprises and their eco-systems in Europe. Country report: Portugal, London: European Commission.

VELOSO, L. (2014): "Profissões, mercado de trabalho e organizações: trabalho social e terceiro setor", Trabalho social profissional no Terceiro Setor, Viseu, Psicoma, pp.181-187.

WORLD ECONOMIC FORUM (2020): The Future of Jobs Report 2020. Geneva- Switzerland. World Economic Forum.

YIN, R.K. (2009): Case Study Research. Design and Methods. Sage, USA.

ZIMMERMANN, A. (2017): "Social Vulnerability as an Analytical Perspective", Social Vulnerability as an Analytical Perspective, Discussion Paper No. 4. 